\title{
13. Fachtagung - FTK - Fertigungstechnologie Kleben Klebtechnik trifft automobilen Leichtbau
}

Am 16. und 17. April 2013 findet die 13. Fachtagung - FTK - Fertigungstechnologie Kleben erstmals parallel zur Fachtagung „Werkstoffe im Automobilbau“ statt. Gemeinsame Veranstalter dieses wichtigen und unverzichtbaren klebtechnischen Branchentreffs sind das Fraunhofer IFAM und die Redaktion adhäsion mit Unterstützung der DECHEMA Fachgruppe Klebtechnik, der Forschungsvereinigung Schweißen und verwandte Verfahren e. V. des DVS, der FOSTA - Forschungsvereinigung Stahlanwendung e. V. und des IVK - Industrieverband Klebstoffe e. V..

- ahrzeughersteller müssen sich bei nur mit stetig steigenden Kundenwünschen, sondern auch mit hohen Umweltanforderungen auseinandersetzen. Die damit verbundenen Herausforderungen werden durch ein strenges Kostenmanagement zusätzlich vergrößert. Um in diesem Spannungsfeld zu optimalen Lösungen zu gelangen, bedarf es der Entwicklung durchdachter Leichtbaukonzepte, deren Umsetzung meist nicht ohne den Einsatz der Klebtechnik gelingt.

Welche Leichtbauziele durch den Einsatz der modernen Klebtechnik heute schon erreichbar sind, vermittelt die 13. Fachtagung - FTK - Fertigungstechnologie Kleben. Einen inhaltlichen Schwerpunkt bilden Vorträge über Anwendungen und Erfahrungen aus der Praxis, aber auch aktuelle Forschungs- ergebnisse und deren Umsetzung. So stehen Präsentationen über die Berechnung von Klebungen und die richtige Vorbehandlung verschiedenster Leichtbauwerkstoffe ebenso im Mittelpunkt wie neuentwickelte Klebstoffe und prozesstechnische sowie qualitätssichernde Aspekte, die beachtet werden müssen, um erfolgreiche Verbindungen zu schaffen.

Um außerdem das interdisziplinäre Zusammenspiel zwischen Werkstoffund Klebtechnikern zu fördern, findet dieser Branchentreff erstmals parallel zur Tagung „Werkstoffe im Automobilbau“ statt. Dadurch besteht die Möglichkeit, sich sehr gezielt sowohl füge- als auch werkstofftechnisch auf den neues- ten Wissensstand zu bringen. Alle Teilnehmer der 13. FTK-Fachtagung und der 4. ATZ-Fachtagung „Werkstoffe im Automobilbau“ können je nach Interesse zwischen beiden Tagungen pendeln.

Begleitet wird die Tagung durch eine Ausstellung, die weitere interessante klebtechnische Anregungen für innovative Verbindungslösungen verspricht. Weitere Infos: www.adhaesionlive.de, adhaesionlive@springer.com

\section{Fachtagung „Industrielle Reinigung“}

Auf der am 14. und 15. März 2013 in München stattfindenden Fachtagung „Industrielle Reinigung“ stellen Experten Maßnahmen und Lösungen vor, die zu einer effizienteren, prozesssicheren Reinigung beitragen.

O b für die Weiterverarbeitung, Wärmebehandlung, Beschichtung, Bauteilprüfung oder Montage - an Werkstücke und Oberflächen werden heute in praktisch allen Industriebereichen hohe Sauberkeitsanforderungen gestellt. Dies macht zum Teil erhebliche Investitionen in Technik für die industrielle Teile- und Oberflächenreinigung erforderlich, die nicht selten zu Kostentreibern in der Werkstückfertigung werden. Dies ist ein wichtiger Aspekt, den die Fachtagung „Industrielle Reinigung“ 2013 am 14. und 15. März 2013 in München thematisiert. Unter dem Motto: „Reinigung beginnt weit vor dem Reini- gungsprozess “ informieren Experten über Lösungen für eine effizientere Reinigung. So stehen Vorträge wie beispielsweise „Reinheitsgerechte Bauteilfertigung“, „Abstimmung des Reinigungsprozesses auf Werkstoff, Geometrie und Reinheitsgrad“, „Entmagnetisierung als Prozessvorbereitung von industriellen Reinigungsprozessen“ und „Optimierte Produktionsprozesse ermöglichen weniger aufwändige Reinigungstechnik“ auf dem Programm. Darüber hinaus bietet die Fachtagung anhand von Praxisbeispielen wertvolles Know-how zu Themen wie „Wässrige Reinigung zur Wiederaufbereitung von Bautei- len“, „Reinigung von Kleinladungsträgern“ sowie zur „Reinigung nach dem thermischen Entgraten“. Den Abschluss des ersten Veranstaltungstages bildet eine Podiumsdiskussion zum Thema „Energieeffizienz in der Reinigungstechnik - lästiges Übel oder wirtschaftlicher Nutzen?“, in deren Verlauf das Auditorium einbezogen wird. Schwerpunktthema des zweiten Tages ist die „Qualitätssicherung und -prüfung “ in der industriellen Teilereinigung. Parallel zur Fachtagung findet eine fachbegleitende Ausstellung statt.

Weitere Infos:

www.industrielle-reinigung.de 